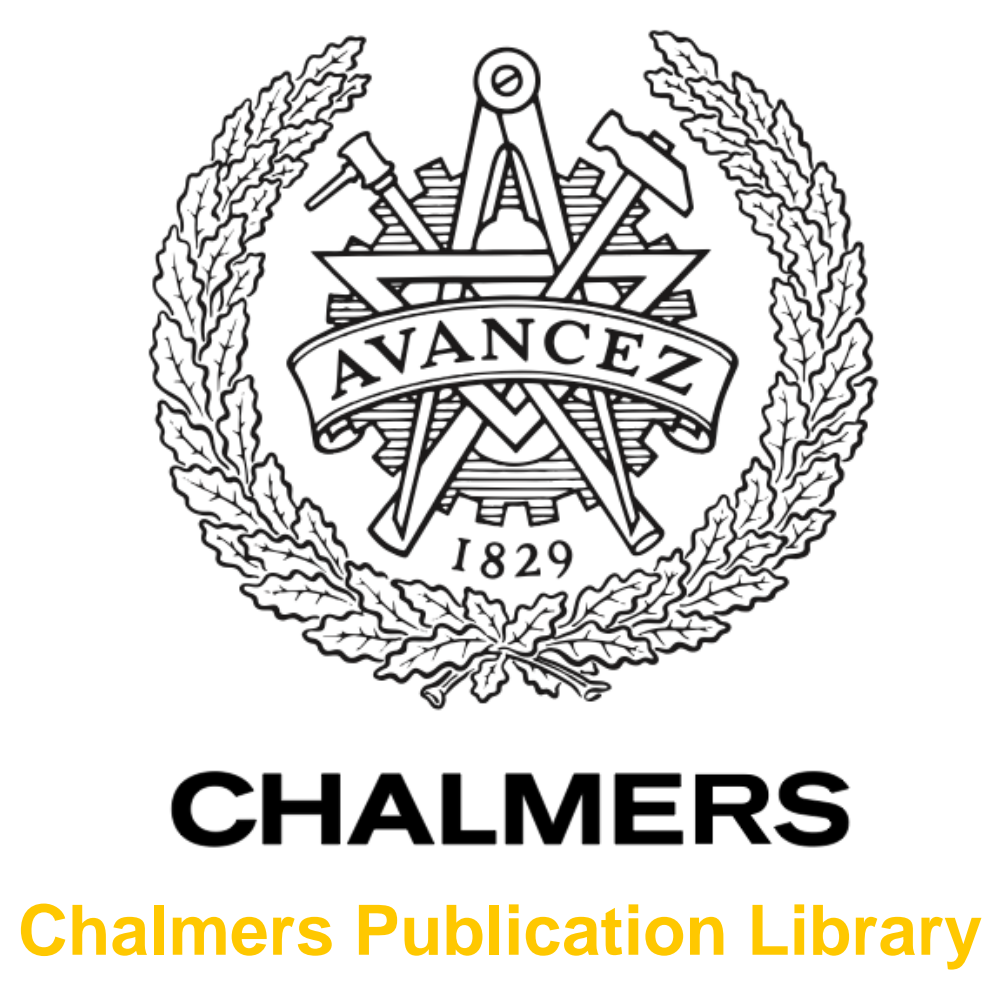

\title{
Technological innovation systems in contexts: Conceptualizing contextual structures and interaction dynamics
}

This document has been downloaded from Chalmers Publication Library (CPL). It is the author's version of a work that was accepted for publication in:

Environmental Innovation and Societal Transitions (ISSN: 2210-4224)

Citation for the published paper:

Bergek, A. ; Hekkert, M. ; Jacobsson, S. et al. (2015) "Technological innovation systems in contexts: Conceptualizing contextual structures and interaction dynamics". Environmental Innovation and Societal Transitions, vol. 16(Sept.), pp. 51-64.

http://dx.doi.org/10.1016/j.eist.2015.07.003

Downloaded from: http://publications.lib.chalmers.se/publication/223400

Notice: Changes introduced as a result of publishing processes such as copy-editing and formatting may not be reflected in this document. For a definitive version of this work, please refer to the published source. Please note that access to the published version might require a subscription.

Chalmers Publication Library (CPL) offers the possibility of retrieving research publications produced at Chalmers University of Technology. It covers all types of publications: articles, dissertations, licentiate theses, masters theses, conference papers, reports etc. Since 2006 it is the official tool for Chalmers official publication statistics. To ensure that Chalmers research results are disseminated as widely as possible, an Open Access Policy has been adopted.

The CPL service is administrated and maintained by Chalmers Library. 


\title{
Technological innovation systems in contexts: conceptualizing contextual structures and interaction dynamics
}

\author{
Anna Bergek ${ }^{\mathrm{a},}$, Marko Hekkert ${ }^{\mathrm{b}}$, Staffan Jacobsson ${ }^{\mathrm{c}}$, Jochen Markard ${ }^{\mathrm{d}}$, Björn \\ Sandén ${ }^{\mathrm{e}}$ and Bernhard Truffer ${ }^{\mathrm{f}}$ \\ aDepartment of Management and Engineering, Linköping University, SE-581 83 Linköping, Sweden. Email: \\ anna.bergek@liu.se. \\ ${ }^{b}$ Copernicus Institute of Sustainable Development, Faculty of Geosciences, Utrecht University, P.O. Box 80115, \\ 3508 TC Utrecht, The Netherlands.Email: M.P.Hekkert@uu.nl. \\ 'Department of Energy and Environment, Chalmers University of Technology, SE-412 96 Göteborg, Sweden. Email: \\ staffan.jacobsson@chalmers.se. \\ dDepartment of Management, Technology and Economics, Group for Sustainability and Technology, Swiss Federal Institute \\ of Technology Zurich, Weinbergstrasse 56/58, 8092 Zurich, Switzerland. Email: jmarkard@ethz.ch. \\ eDepartment of Energy and Environment, Chalmers University of Technology, SE-412 96 Göteborg, Sweden. Email: \\ bjorn.sanden@chalmers.se. \\ fDepartment of Environmental Social Sciences, Eawag, P.O. Box 611, 8600 Dübendorf, Switzerland. Email: \\ Bernhard.Truffer@,eawag.ch.
}

This is a post print version. Please refer to the published article:

Bergek, A., Hekkert, M., Jacobsson, S., Markard, J. Sandén, B., Truffer, B., 2015.

Technological innovation systems in context: Conceptualizing contextual structures and

interaction dynamics, Environmental Innovation and Societal Transitions, 16: 51-64

(http://doi.org/10.1016/i.eist.2015.07.003).

(C) 2015. This manuscript version is made available under the CC-BY-NC-ND 4.0

license http://creativecommons.org/licenses/by-nc-nd/4.0/

\begin{abstract}
This paper addresses interactions between technological innovation systems (TIS) and wider "context structures". While TIS studies have always considered various kinds of contextual influences, we suggest that the TIS framework can be further strengthened by a more elaborated conceptualization of TIS context structures and TIS-context interactions. For that purpose, we identify and discuss four especially important types of context structures: technological, sectoral, geographical and political. For each of these, we provide examples of different ways in which context structures can interact with a focal TIS and how our understanding of TIS dynamics is enhanced by considering them explicitly. Lessons for analysts are given and a research agenda is outlined.
\end{abstract}

Keywords: technological innovation system, context, sector, geography, politics, transition 


\section{Introduction}

Over the past three decades, system concepts have gained prominence in the academic literature on innovation processes and in associated policy-making (Chang and Chen, 2004; Sharif, 2006). These approaches have proven to be instrumental for informing a wide range of pressing public policy problems, such as national economic competitiveness, regional industrial revival and global environmental sustainability.

The specific variant of technological innovation systems (TIS) focuses on understanding how the innovation system around a particular technology functions. The focus can be on mature technological fields or on the emergence and diffusion of new and radical innovations (Bergek et al., 2008b; Carlsson and Stankiewicz, 1991; Hekkert et al., 2007; Markard and Truffer, 2008). A large part of the studies applying the TIS framework have focused on studying the emergence of clean-tech sectors and, by this, it has become a major building block of sustainability transitions research (Markard et al., 2012). In the field of transition studies, TIS contributes with an analytical framework for understanding the complex nature of the emergence and growth of new industries and a focus on analyzing obstacles to this process (labelled blocking mechanisms, system weaknesses or systemic problems). The framework also contributes to the subsequent translation of obstacles into intervention and policy strategies, which has led to concepts such as systemic instruments and policy mixes (Alkemade et al., 2011; Jacobsson and Karltorp, 2013; Smits et al., 2010; Weber and Rohracher, 2012; Wieczorek and Hekkert, 2012).

As a technology-centred framework, there has always been a focus on technology-specific factors in TIS research. However, since it is a systems approach analysts have from its inception tried to find ways to take into account interactions with other types of systems encompassing or transcending the TIS, such as sectoral and national systems of innovation. Indeed, the 'functions approach' was developed as a methodological tool to handle this complexity by aggregating various influences (of different origins) on the dynamics of a TIS into a set of key processes (Hekkert et al., 2007; Jacobsson and Bergek, 2006; Johnson and Jacobsson, 2001). This has allowed for a large number of detailed empirical analyses of how the dynamics of various TISs have been influenced by internal and external pushes and pulls (for reviews, see Bergek, 2012; Truffer et al., 2012).

At the same time, the functions framework does not give much explicit attention to the dynamics of surrounding contexts. In recent years, TIS scholars have therefore returned to the relationship between TISs and contextual systems. Scholars have developed the geographical dimension further (e.g. Binz et al., 2014; Coenen et al., 2012; Gosens et al., 2015; Schmidt and Dabur, 2014), studied the parallel development and competition of several technologies (Johnson and Jacobsson, 2001; Sandén and Hillman, 2011; Suurs and Hekkert, 2009a; Wirth and Markard, 2011) and linked TISs to wider policy settings (Kivimaa and Virkamäki, 2014; Markard et al., in press; McDowall et al., 2013). Some have also made a plea to combine the TIS framework with the Multi-Level Perspective to better capture the 
relationship between technology evolution and sectoral change (Markard and Truffer, 2008; Meelen and Farla, 2013).

While these studies have all contributed to a better understanding of how a TIS relates to various context structures we still lack a coherent framework that makes explicit how the interactions between a TIS and its contexts can be conceptualized. Such a framework would have at least four clear benefits. First, it would improve the TIS framework as a policy tool in that an improved contextual understanding would guide analysts in their search for central interactions between a focal TIS and its context. Second, it would increase the awareness among analysts and policy-makers that contexts vary widely and that technologies develop differently in different contexts. Explicit consideration of contexts would, thus, increase our understanding of the particularities of individual case studies and, at the same time, provide a basis for a classification, generalization and transfer of findings, which is of key importance for TIS-based policymaking. Third, by acknowledging that context structures are not static but change over time, it would allow analysts to identify particularly favourable (or unfavourable) opportunities for development of new technologies. Fourth, a coherent framework incorporating context structures would facilitate further analytical work with a focus on how a given TIS (or set of TISs) impacts on different contexts. Hence, an additional benefit may be to pave the way for the development of a TIS-based framework which is helpful for analyzing larger transitions involving the growth and decline of several technologies and associated sectoral transformation processes.

The aim of this paper is to take a step towards a more explicit framework for analysis of TIS-context interactions by addressing the relation between a TIS and four different context structures. We also formulate a set of questions that may form the backbone of a research agenda. The selected contexts include other TISs, industrial sectors, geographical territories and political systems.

In section 2, we discuss some general aspects of system delineation and interaction and motivate the choice of the four analyzed context structures, while section 3 provides examples of how technological, sectoral, geographical and political structures interact with TIS dynamics and identifies a set of research questions. Section 4 concludes the paper by discussing some general lessons for analysts.

\section{Understanding TIS context structures and interactions}

A technological innovation system is defined as a set of elements, including technologies, actors, networks and institutions, which actively contribute to the development of a particular technology field (e.g. a specific technical knowledge field or a product and its applications) (cf., e.g. Bergek et al., 2008c; Markard and Truffer, 2008). The TIS perspective emphasizes systemic interdependencies between these elements, which give rise to various forms of synergies, such as collective assets on which the different actors can draw but which they could not produce if they worked in isolation. 
The existence of system-level assets (or resources, see Musiolik et al., 2012) implies that system boundaries have to be carefully chosen. The boundary separates the TIS (i.e. the realm where systemic interdependencies in a specific technological field play out) and its "context" (all other structures and relevant factors outside of the TIS). In the literature, the setting of system boundaries is largely considered to be an analytical problem, i.e. system boundaries can be set in many different ways depending on the research interest of the analyst and often have to be adjusted as the analysis proceeds (Bergek et al., 2008a; Carlsson et al., 2002). In principle, the aim of boundary setting is to determine what technology and what level of analysis (a knowledge field, a product or one or more applications of the technology) is in focus (Carlsson et al., 2002). It is also common in empirical analyses to use some kind of geographical delimitation, e.g. a region or a country, but it should be noted that this does not follow from the definition of a TIS (Bergek et al., 2008b; Carlsson et al., 2002). In the following, we will call an analytically delimited object of analysis a "focal TIS".

Structures and processes inside a focal TIS are generally well conceptualized in the literature. As explained in the introduction, what happens outside and across the system boundary has been less systematically worked out. In the present section, we therefore aim at identifying different types of relevant interactions that cross TIS boundaries and can give rise to coupled dynamics between a TIS and various contextual structures. We distinguish two broad kinds of TIS-context interactions, here termed "external links" and "structural couplings", which refer to different degrees of interdependence. The distinction between these is rather a gradual one than a clear-cut differentiation. The main question to consider is essentially whether actors of a TIS can influence the underlying context elements or not. ${ }^{1}$

We denote as external links those influences (or resources, assets) between a TIS and a specific context that impact the development of a TIS, but which are not affected by TIS-internal processes. Such links can for instance be conceptualized as "landscape" forces (cf., e.g. Geels and Schot, 2007) in the sense of macro level developments far outside of the focal TIS. Examples are sudden price shifts in essential production factors, major technical disasters, fundamentally changing political priorities in a society, etc. Besides these distant forces, external links can also be nearer to the influence of the focal TIS, such as national policies affecting knowledge generation or market conditions as well as the availability of physical infrastructure, a well trained work force or supportive public discourses (e.g. Climate Change in the case of renewable energies). As a general rule, we may assume that over time those context structures that are nearer to the influence of TIS-internal processes may over time turn into structural couplings (see below). In the extant literature, external links have often been addressed as blocking or inducement mechanisms (Johnson and Jacobsson, 2001), and they have, thus, been accounted for in relation to the TIS functions.

\footnotetext{
${ }^{1}$ In the long run - as a TIS matures and expands - external links may be internalized and turn into structural couplings (see below). However, at any given moment in time it should always be possible for the analyst to distinguish between the two types.
} 
Even though external links mostly work from the context to the TIS, we may also consider influences in the other direction. However, this situation is much rarer - especially in early maturation phases. An example could be a situation in which the existence of a TIS serves as legitimation for incumbent sector actors to maintain their investments in conventional technologies, for instance if they can use the TIS to show that they are "doing something" or that "the technology is not really working". Both examples can be found in much of the recent history of alternative drive trains in the automobile sector (Wesseling et al., 2014).

An influence of the second, and more significant, kind of interaction is mediated by "structural couplings" , i.e. shared elements (actors, networks, institutions, technologies) between a TIS and specific context structures. Structural couplings exist due the fact that most TIS elements do not exist for the sole purpose to promote the technology under consideration. ${ }^{3}$ Instead they are typically embedded simultaneously in several different contexts. Think of a firm that sells a whole series of products (e.g. food and clothes) and manages a whole portfolio of alternative innovation processes. This firm may be part of a specific TIS (e.g. for organic food), while at the same time (and even more importantly) having to respond to developments in a specific sector (retail in this case), being active in different policy domains and having to manage value chains that stretch globally. This means that the decisions and strategies of "shared" actors cannot be explained by their membership in the focal TIS alone, but will depend on a complex interplay of firm-internal decision processes balancing the tensions and trade-offs among different goals it wants to achieve in different areas. The firm can thus be seen as a coupling structure between the TIS and different contexts, which has to compensate for dynamics in these different realms. Networks and institutions may also act as structural coupling elements (Johnson and Jacobsson, 2001). An example is the feed-in tariff in Germany, which represents a complex compromise of the interests of different renewable energy advocates and broader concerns of political parties, energy sector incumbents and other stakeholders (Lauber and Mez, 2004).

Couplings may involve single elements or even a whole range of elements. This opens up the possibility for a whole gradient of system overlaps, ranging from fully independent to very strongly resonating systems. A TIS in which many of the elements - or a few very essential ones - have couplings to context structures can be heavily influenced by these structures and can also influence them in return. This implies that structural couplings can give rise to interdependent dynamics between a focal TIS and various context

\footnotetext{
${ }^{2}$ In previous literature, the largely synonymous term of "structural overlaps" has been introduced (see Bergek et al., 2008c; Sandén and Hillman, 2011). However, here we prefer to use structural couplings in order to emphasize the potential impact that these elements may have on the respective dynamics of TIS and contexts.

${ }^{3}$ Claiming that all TIS elements are supposed to exist only to promote a technology would correspond to a very naive reading of the TIS literature and one that ultimately led to an accusation of "functionalism". This misinterpretation has recently been clarified (see Jacobsson and Jacobsson, 2014).
} 
structures, where the dynamics observed in a specific context may impact the development of a TIS and vice versa. ${ }^{4}$

As a general rule, one would assume that TIS elements that incorporate many structural couplings are more constrained with regard to their strategic leeway in contributing to a specific TIS compared to those elements that only exhibit a few exogenous ties. Examples could be i) internal conflicts of interest within a specific organization participating in the TIS, which limit the range of actions and strategies that this actor can develop in the context of the TIS (think of an automobile manufacturer engaging in zero emission vehicle innovation while still wanting to keep high sales numbers in conventional technologies), ii) constraints in the alliances that TIS actors establish, which can contain conflicting or synergistic relationships with other context structures (e.g. electric utilities not engaging in an association for an ecolabel for renewables because this would jeopardize their political position on promoting nuclear power as climate friendly), iii) the limited flexibility of institutions that have emerged to support dominant technological paradigms and that are difficult to change to meet the needs of an emerging technology (e.g. mandatory connection laws for households to public sewers that lead to double payment for households that want to treat their waters on site) and iv) limited flexibility of existing physical infrastructures which new technologies have to share and to which they, therefore, have to be adapted (e.g. in the paper and pulp and lighting industries (cf. Karltorp and Sandén, 2012; Onufrey and Bergek, 2015)).

However, a strong coupling to existing context structures could also facilitate - or even be necessary for the development of a new technology (Onufrey, 2014). In fact this might be the essence of technology evolution (cf., e.g. Arthur, 2009). A higher degree of structural couplings might, for example, increase the ability to get access to assets existing in the context. It is therefore impossible to a priori determine whether structural couplings are positive or negative characteristics of a TIS element.

The degree to which the agility of a TIS element will be constrained or enabled also depends on the institutional coherence of the respective context structure (Fuenfschilling and Truffer, 2014). These different contexts can be conceptualized as organizational fields (Wooten and Hoffmann, 2008). An example of identifying the institutional coherence in economic sectors like energy supply, transportation, health care or agriculture, is provided by the concept of a socio-technical regime (Geels, 2002; Rip and Kemp, 1998). Regimes correspond to the strongly institutionalized core of an organizational field, which may encompass dominant technological paradigms but also specific professional identities, commonly held beliefs, a sectoral culture, dominant societal discourses or shared problem agendas which give rise to a specific mix of institutional logics (Fuenfschilling and Truffer, 2014). Other examples of coherent

\footnotetext{
${ }^{4}$ It should be noted that we are here referring to system-level dynamics. We would not speak of TIS-context interaction if only individual actor strategies or policies were affected.
} 
contextual systems may encompass other technological fields or industries as well as political systems, geographical systems, legal systems, science and education or financial systems.

So far we have referred in a rather undifferentiated way to "different context structures" without specifying what these could be. We will now introduce three generic types of contextual structures before we will select four specific examples for our further analysis.

A first type of context structure includes surrounding and related TISs. To some extent this TIS-TIS relation emerges as a direct consequence of how geographical and technical system boundaries of a focal TIS are defined. The European PV TIS, for example, represents a context for the German PV TIS as well as for the European thin-film PV TIS. However, contextual TISs are not just an issue of delineation but also depend on technology interaction more broadly. Different technologies compete and complement each other in various ways, which means that the coevolution of several TISs will influence the dynamics in each one of them (see also Sandén and Hillman, 2011). Hence, each TIS forms a potentially important context of other TISs.

A second type of context structure can be associated with pre-existing infrastructures and institutions, e.g. in specific sectors or in regional or national contexts. As a new technology emerges, it has to be embedded into (some of) these broader structures, which have typically developed over long periods of time and for a broader class of technologies or public policy goals. An example could be the influence of a specific variety of capitalism in a country on the way in which a technology is promoted (Garud and Karnøe, 2003), or the different technological trajectories that unfold depending on which sector the technology is primarily trying to accommodate to (as in the case of biogas in Germany, which started as an agricultural technology and became more and more of an energy technology in recent years, see Markard et al. (2014)).

Third and finally, we may identify context structures that are related to the provision of specific systemlevel assets. Think of political support for technology-specific policies, the need for trained personnel or the provision of venture capital. In each case, a focal TIS will have to interact more or less intensely with the political, educational or financial system, respectively. Each of these may exhibit very particular constraints and dynamics, which impact the further development of a TIS.

The rest of the paper elaborates on TIS-context interactions for four exemplary context structures: other TISs (first kind), sectoral and geographical structures (second kind) and political structures (third kind). We are aware that these contexts are not necessarily neatly separated (since technological, sectoral, national and political structures may overlap strongly) and that other potentially relevant context structures exist that we do not address. We will return to these limitations in the concluding section. As a final note of caution, we admit that the distinction between a focal TIS and different context structures is often "blurred" and, therefore, not a straightforward exercise (Bergek et al., 2008c; Markard and Truffer, 2008). Even though some system boundaries in some cases appear to be more "natural", the focal TIS 
and its contexts are always constructs of a specific analytical choice. TIS and context delineation can also be viewed as emerging out of an iterative process; the system boundaries can be redrawn after the discovery of new relationships, which may uncover yet other relationships. It is also possible to work with systems at different levels of aggregation in parallel to uncover different types of dynamics (Bergek et al., 2008c).

\section{Interactions between a focal TIS and four context structures}

\section{I Interaction between a focal TIS and other TISs}

Technologies complement each other, compete and, thus, interact. This is particularly important for sociotechnical transitions with multiple technologies emerging and declining at the same time. As a consequence, we can think of the context as a large set of 'other' TISs that interact in different ways with the focal TIS. Some of these interactions are competitive, i.e. actors in two different TISs compete for market shares or strategic assets (e.g. raw materials, labour, capital or legitimacy) and other interactions are supportive (i.e. what happens in one TIS has a positive influence on another TISs) (Sandén and Hillman,

2011). For example, photovoltaic cells are complemented by recent progress in battery technology, while it competes with both wind and nuclear energy.

TISs in the context can be conceptualized in the same way as the focal TIS. They consist of technologies, actors, networks and institutions pertaining to a specific technological domain. Also, similar procedures for delineation apply (cf. Bergek et al., 2008b): it is an iterative process guided by research interests but also by actual interdependencies that can only be identified empirically. As the analyst concentrates on a particular part of the technology value chain, on a particular region or on a particular technological scope, this defines the focal TIS and automatically assigns all remaining parts (or systems) to the context. Which of these are relevant for the subsequent study, however, is very much an empirical question and may very well change over time as the focal technology diffuses and matures (or declines).

Much of the TIS-TIS interaction occurs along vertically related technology value chains. A focal TIS typically requires raw materials, components, sub-systems and services that are provided by other TISs, which implies that the development of the focal TIS could be affected, positively or negatively, by the development in upstream TISs. For example, a change in the technical characteristics of a component supplied by a contextual TIS may be pivotal for the focal TIS and any change in in the product of the focal TIS can enforce changes in the products of its suppliers, i.e. influence 'knowledge development' and 'the direction of search'. Other things may spill over as well, such as when the environmental characteristics of rare earth metal extraction threatened to negatively influence 'legitimation' for wind power due to the use of rare earths in some generator magnets. Such interactions are often complementary, i.e. progress in a contextual TIS affects the focal TIS in a positive way (in terms of, e.g. higher production capacity, better quality or lower prices). However, up- or downstream TISs can also 
become bottlenecks for 'knowledge development' in the focal TIS, for example if complementary technologies do not develop at the same pace as the focal TIS. ${ }^{5}$ Similarly, many focal TISs deliver products that are used by one or more downstream TISs (rather than by end users) and the demands and requirements of these TISs can, for example, 'influence the direction of search' of the focal TIS at the same time as the focal TIS can influence the rate and direction of developments in downstream TISs.

To the extent that supplier TISs provide general-purpose goods and services (say steel or magnets) for use in many TISs beside the focal TIS (say wind turbines) and buyers are in no way devoted to the output of the focal TIS, vertical interactions would be of external-links character. However, in some cases structural couplings emerge across different parts of the value chain, e.g. in the form of firms collaborating closely (e.g. through joint ventures or "development pairs" (Fridlund, 1993)) or even integrating vertically forwards or backwards (e.g. through acquisitions) in order to achieve high degrees of coordination or to control critical inputs or markets. For example, in the emerging PV TIS around 2007 and 2008 when growth rates were extremely high and silicon became a scarce resource, many European solar cell producers made long-term contracts with Si-producers from the chemical industry or even bought Siproduction facilities to secure continuous supply. Structural couplings can result in 'knowledge diffusion' between actors, 'resource mobilization' (e.g. in the form of labour mobility) between TISs and spillovers concerning institutional elements, such as expectations and customer preferences, which can influence 'market formation' and 'legitimation' of the focal TIS. Where critical parts of the value chain are controlled by certain kinds of firms, this can have profound implications for the development of novel technologies (and their proponents). In the pharmaceutical industry, for example, incumbents control market channels and the financial assets needed to commercialize new technologies and new biotech companies therefore have to enter into alliances with incumbents if they want their technologies to reach the market (Rothaermel, 2001).

Interaction can also occur between a focal TIS and horizontally related TISs. This refers primarily to TISs that draw on the same inputs and complementary assets or provide similar outputs as the focal TIS. For example, in the case of biogas, energy crops and cultivation of food compete for the same main asset, which is arable land. In a similar vein, wind and hydropower are competing technologies as they generate the same product (electricity). Such relationships typically result in competitive, external-link type interactions, but structural couplings can also emerge (especially over time). The latter can, for example, take the form of delegitimation of rival technologies through organized lobbying work, as in the case of biofuels in the Netherlands, where proponents of second-generation biofuels actively tried to decrease legitimacy of first-generation biofuels (Suurs and Hekkert, 2009b; Ulmanen, 2013). Horizontally related TISs can also be structurally coupled through institutions. A case in point is the German feed-in tariff to promote a broad range of different renewable energy technologies. It provides financial resources,

\footnotetext{
${ }^{5}$ For a discussion about the importance of component and complementary technology development for the development of complex products, see Brusoni et al. (2001).
} 
guidance and legitimacy, thus having a major impact on several TISs, including wind power, solar, biogas, cogeneration and others. As a result, the various TISs are (indirectly) coupled through this regulation. Indeed, advocates of these different TISs joined forces and worked together to initiate, maintain and strengthen the feed-in tariff, in spite of the fact that they were essentially competitors (Jacobsson and Lauber, 2006) (see also Section 3.2). Only very recently, following a controversial debate about the costs of these subsidies, technology competition has become more prominent as actors from the PV and onshore wind turbine TISs started to delegitimize offshore wind, which is still very expensive and requires higher feed-in tariffs.

This points to another important aspect of TIS-context interactions: They tend to change over time, both as a matter of autonomous developments in context structures and as a consequence of the focal TIS growing and becoming more mature. In fact, in early stages of TIS development we expect the TIS to depend very much on developments in its contextual TISs. These context TISs are, on the other hand, only marginally affected by the emerging TIS, especially if they are established and rather mature. In later stages, however, dependency may become more equal, which means that actors and institutional structures in contextual TISs will be affected by the development of the focal technology.

By including a more elaborate analysis of the interaction between the focal TIS and other TISs a whole new range of research questions emerge like: 1) What is the influence of TIS-TIS competition on the focal TIS and the role of policy in magnifying or balancing competitive forces (Hillman et al., 2008; Wirth and Markard, 2011)? 2) What are the typical types of struggles between actors from different innovation systems (Suurs and Hekkert, 2009a)? 3) Under what conditions do actors in competing TISs decide to run in packs and collaborate for institutional reforms (Bergek et al., 2008c; Jacobsson and Lauber, 2006)? 4) How do technological improvement and infrastructure developments in one TIS influence the success chances of other TISs, e.g. when are forerunners acting as 'bridging technologies' that pave the way for others and when do they lock competitors out of the market (Andersson and Jacobsson, 2000; Sandén and Hillman, 2011)? 5) What synergies (rather than competition) can occur between emerging and more established TISs (Haley, 2015)?

\subsection{Interaction between a focal TIS and relevant sectors}

As was noted in Section 1, it has long been recognized that the dynamics of a given TIS is intertwined with the structure and dynamics of the sector(s) of which it is a part. This understanding is not only found in the literature on innovation systems (cf. Johnson and Jacobsson, 2001; Malerba, 2002), but also in the concept of socio-technical regimes (cf. Geels, 2004; Kemp et al., 1998; Smith and Raven, 2012). In this paper, we define sectors in terms of the production, distribution and use of technologies and products needed to serve a certain function for prospective users, e.g. supply of medicines (Malerba, 2002), energy or food (cf. Geels, 2004). Sectors are composed of the same type of structural elements as TISs, but they rely on a larger set of technologies in different stages of maturity - and, consequently, on several different 
TISs - to provide their overall function. They tend to exhibit high degrees of institutionalization in terms of well-defined division of labour and stable network relationships between supply-side actors, clear user practices, preferences and buyer-supplier relationships, sector-specific regulations and technological infrastructures (Malerba, 2002; Smith and Raven, 2012). A sector therefore provides a quite stable context, which individual TISs either have to adapt to or try to change to their own benefit.

Let us first consider a focal TIS that is clearly embedded in one main sector, i.e. its products mainly contribute to serving that sector's overall function. For example, the wind turbine TIS develops products that are used to generate electricity and can, thus, be considered to be part of the energy sector. Such a TIS can be more or less integrated with the sector. At one extreme, the TIS is niche-like, i.e. it consists of TIS-specific actors, networks and institutions that do not participate much in sectoral affairs. Most TISsector interactions will then be of the external link type (which to some extent has been discussed in previous TIS literature). At the other extreme, the TIS will be so integrated with the sector that it might not even be interesting to analyze it as a separate TIS. In between these extremes, the focal TIS both has technology-specific elements and elements that are coupled with sectoral structures. This is the situation we are interested in here. Such TISs can be connected to sector-level structures in a variety of ways.

With regard to actors, some incumbent users might be competent enough to participate in the development of specific new technologies by defining their needs or even co-creating solutions to meet those needs. Such "lead users" (von Hippel, 2005) can influence the 'direction of search' within a TIS. For example, in the field of factory automation, Carlsson and Jacobsson (1994) pointed at the key role of advanced customers in the innovation process and in the field of wind power the Swedish energy company Vattenfall was early on involved in the development of wind turbine technology, which guided the development (and 'resource mobilization') toward MW turbines (Bergek and Jacobsson, 2003). However, incumbent users can also obstruct the development of an emerging TIS by blocking its access to resources or by delegitimizing it (Johnson and Jacobsson, 2001). Less competent users can also influence a focal TIS. For example, energy consumers can influence 'market formation' for a wind turbine or solar cell TIS by starting to produce their own energy using these technologies.

Sector-level networks, such as lobbying organizations, industry associations or collaborative research networks, can influence 'legitimation' and 'guide the direction of search' of all TISs associated with a sector. ${ }^{6}$ If actors of a focal TIS participate in such networks, they can potentially influence agendas to the benefit of the TIS, for example by making sure that part of the budget of a research institute is spent on TIS-relevant research. An example is presence of different renewable energy consortia in the Dutch Top Sector Energy (see www.topsectorenergie.nl), which decides on how to distribute R\&D funding to key players in the Dutch energy sector. Several consortia that focus on specific renewable energy technologies

\footnotetext{
${ }^{6}$ Networks can also span sectoral borders. For example, some actors from the energy sector have joined forces with actors from shipping and fishing to block legitimation of offshore wind power (Jacobsson and Karltorp, 2013).
} 
like offshore wind and PV have managed to get fully embedded in the Top Sector Energy and thereby have an important say in the distribution of research funding.

Shared technological assets, such as physical infrastructures or joint sectoral knowledge bases tend to be designed to serve established technologies and can, therefore, influence the initial 'direction of search' of emerging TISs (Unruh, 2000). The current electric grids are, for example, designed for a one-directional supply of electricity from centralized plants, and to some extent discriminate against distributed electricity production. In addition, sector-level technological trajectories (cf. Dosi, 1982) can influence the 'direction of search' for individual technologies. One example is the lighting sector, where a continuous focus on increasing energy efficiency has stimulated both the emergence of new lamp technologies over time (e.g. halogen, CFL and LED) and the development of new and gradually improved product generations within each TIS (Onufrey, 2014). At the same time, the energy efficiency trajectory has been gradually reinforced by the successes achieved by individual TISs.

Finally (and perhaps foremost), interactions occur between a focal TIS and sector-level institutions. These include sector-level policies that influence framework conditions in the sector as a whole, such as liberalization policies in many infrastructure sectors, which open up or close markets for new technologies ('market formation') and affect the strategies of incumbent actors in their dealing with new technologies ('influence on the direction of search') (Lieberherr and Truffer, 2014; Markard and Truffer, 2006). Sectorlevel institutions also include laws, regulations and economic support systems aimed at all or most technologies in a sector, e.g. emissions or performance standards, which influence 'market formation' as well as the 'direction of search' to or from specific TISs. Some of these have technology-specific components or rules, which creates structural couplings with the affected TISs. For example, the Swedish tradable green certificate system, which in principle applies to all renewable electricity production, has technology-specific rules about which hydropower plants can receive certificates and, similarly, the German feed-in law differentiates between technologies in terms of fixed-price levels.

Norms and values at the sectoral level, such as user preferences and practices or dominant sectoral discourses, can also influence individual TISs, in particular in terms of 'legitimation'. One case in point is the focus on range as a key performance dimension of cars and the discussion on range anxiety in relation to electric vehicles. Another example is the dominance of the nuclear power issue in the Swedish energy debate, which has put the legitimacy of all renewable energy technologies into question (Jacobsson and Bergek, 2004). However, the 'legitimation' of incumbent sectoral technologies and technologies being developed by emerging TISs are often intertwined. As emerging TISs become more established they can challenge existing sectoral norms and regulations. For example, when the German feed-in law was questioned by the incumbent utilities in the 1990s, actors from several renewable energy TISs worked together and were able to keep the feed-in law in place (Bergek et al., 2008c; Jacobsson and Lauber, 2006). 
Many TISs are part of several sectors. For example, biomass-based transport fuel TISs are primarily part of the transport sector (which uses the fuels), but are also related to the automotive sector (which produces the vehicles in which the fuels will be used), the agriculture and forest sectors (which produce the input to fuel production) and the energy sector (since the fuels can also be used to produce heat and electricity). This implies that interactions do not only occur with the sector the focal TIS is mainly embedded in, but also with other sectors that it is related to. In particular, actors that enter an emerging TIS often come from other sectors. This also applies to buyers. For example, buyers of renewable energy technologies are often diversifying into electricity production from other industries and sectors, e.g. pulp and paper, food, agriculture, forestry, real estate and manufacturing (Bergek et al., 2013). Because of such structural couplings, sectoral dynamics in adjoining sectors can influence the actions of both suppliers and users in the focal TIS and, thus, its functional dynamics. ${ }^{7}$

As the discussion above has shown, an explicit analysis of relevant sectoral context structures and their interactions with a focal TIS through external links and structural couplings is needed in order to fully capture TIS (and sector) dynamics. Such an analysis opens up for a range of research questions. First, it raises the question of how incumbent sector actors who are not part of a focal TIS influence its development. Previous literature has primarily emphasized incumbents' (active) resistance to change, but as the discussion above indicates, the situation might be more complex than that. Second, when structural couplings exist, TIS-sector interaction is not necessarily unidirectional. How do emerging TISs influence sector-level structures, in particular if and when they start to grow rapidly? Third, if a TIS is associated with several sectors their influences are not necessarily reconcilable. Depending on which sector the TIS primarily adapts to it can therefore be pulled in different directions. An important question is then what the consequences are for the focal TIS of being linked up to different sectors.

\subsection{TIS development in geographical context structures}

It is a trivial fact that structural elements of a TIS are always localized somewhere in space. As a consequence, TIS boundaries will often coincide with territorial limits. For instance, if wind power was primarily developed in Denmark, it will be very natural to search for favourable conditions that were provided by political, social and economic structures that already existed in that very same country. ${ }^{8}$ Geographical context may, therefore, as a first step be seen as relating to the setting of TIS boundaries and by external links that may exist between a TIS and resources located in a specific territory. In this interpretation, geographical context have always been part of TIS analyses, even though mostly implicitly.

\footnotetext{
${ }^{7}$ Adding further complexity, it should be noted that the importance of different sectors for the focal TIS might change over time. For example, agricultural biogas in Germany was originally conceived as a novel technology addressing pressing problems in the agricultural sector. As the TIS matured, biogas became more and more aligned with the needs of the energy sector and the resulting expansion in the use of energy crops created negative repercussions in the agricultural sector, which weakened the 'legitimation' of the TIS there (Markard et al., 2014). ${ }^{8}$ For a lucid comparative analysis of the relative importance of the Danish and US contexts, see Garud and Karnoe (2003).
} 
In particular, dealing with geographical context gets rather unproblematic for an analyst if the relevant technological, sectoral and political context structures overlap in a territory (e.g. a specific country). Then this country may be treated as a shorthand denomination for all different contexts. As a matter of fact, most empirical applications of the TIS concept have focused on the national scale (Coenen et al., 2012) or, at most, endeavoured comparative analyses of two or several nationally delimited TISs (Bergek and Jacobsson, 2003; Lovio and Kivimaa, 2012; McDowall et al., 2013; Negro et al., 2007; Vasseur et al., 2013).

However, interactions between a focal TIS and geographical contexts get quite a bit more complex if we focus on two further problems that are associated with geography as context (Truffer and Coenen, 2012): i) structural couplings that lead to the embedding of TIS structures in a specific territory (think of a firm that proactively develops a new technology and is at the same time very actively supporting the education of the regional labour force, or farmers that adopt a cooperative management system for biogas because they have developed a culture of sharing machines and resources with their local neighbours), and ii) structural couplings that relate to actors, networks and institutions that interconnect different places (e.g. in the case of transnational companies or globalized value chains).

First, TIS actors, networks and institutions will typically be embedded in structures that pre-exist in a specific territory. In a nutshell, geographical territories - nation states, regions, cities, or associations of states (like the US or the EU) - can be seen as the historical result of organizational and institutional alignment processes (involving industrial sectors, cultural norms, formal regulations, educational systems, labour markets, political systems, etc.) and natural context conditions. These territories often host distinctive cultural communities with specific institutional arrangements that guide cooperation, competition and/or innovation. As a consequence, TIS elements may get structurally coupled with these territorially aligned elements. Take for instance, building codes which may represent major barriers for the instalment of spatially extensive energy technologies like renewables. Building codes have developed over historical time periods, integrating specific regional or national political priorities related to housing needs, industrial development, landscape and nature protection, as well as livelihood and aesthetic considerations. The instalment of renewable energy technologies may be strongly impacted by these codes and in that case they represent external links. TIS actors will have to try to either adapt to or change specific regulations within these building codes. In the latter case, building codes will represent a structural coupling. This coupled dynamics of TIS and building codes is on the one side affected by all other considerations that are associated with regional building codes and on the other side the codes may be changed in a way that might have unintended consequences in other areas (e.g. a changed perception of aesthetic perceptions of roof surfaces or physical landscape). Other examples may be professional or regional cultures which may impact the shape of technological trajectories in specific local contexts (Wirth et al., 2013), which may in turn shift the professional identify and local culture of farmers when 
renewables gain an increasing share of the average farmer's activities (as in the recent shift from food farming to energy farming in Germany, see Markard et al. (2014)).

An example of the relevance of a geographically differentiated view on embedding has recently been presented for explaining how PV market formation developed so forcefully in Germany. The usual explanation refers to the instalment of a strong nationally uniform market pull policy, the feed in tariff for renewable energies. A recent study argued that this explanation ignored the very basis of the legitimacy that enabled the strong support policy to become politically acceptable in the first place (Dewald and Truffer, 2012). This research showed that a decade prior to the introduction of a national feed-in tariff, local citizen groups all over the country (so called solar civic associations) engaged in a broad range of market formation activities, which were decisive for the overall PV-TIS development in Germany (Dewald and Truffer, 2011). These initiatives educated early adopters and worked as system integrators, putting different technological components into working PV systems and taking care of installing, maintaining and financing the panels. They furthermore engaged in marketing activities and lobbied for local support policies. Being members of the same communities (a strong structural coupling), they could overcome barriers to market formation that would have been near to impossible for a nationally active interest group. One of the core assets they could build on was established trust relationships among the local people, which enabled them to relate to the cultural context and build up legitimacy, ensure very intimate knowledge exchanges between early suppliers and customers with regard to technical and financial reliability, negotiate with local traders to prove how to make a business out of PV and even get elected into the communal parliament to promote certain policies. In sum, we may say that each organization constructed local TIS structures (here mostly related to market formation) by embedding them in their specific local context. By this they could present local "proofs of feasibility" (in technical as well as cultural and economic terms) for a functioning PV trade, which provided income for local firms, political legitimacy to political parties and happy customers and citizens. When the national feed-in tariff was finally introduced, it could build on a strong legitimacy basis established independently in a broad range of local contexts and therefore gain momentum without much political contestation.

Local embedding promises to open up a number of new perspectives on TIS formation. The structural coupling between a focal TIS and different territorial innovation systems may give rise to interesting dynamics and provoke questions about synergies between technology and regional policies, or the contribution of local and regional initiatives to promote sustainable development. A particularly promising avenue of research opens up with regard to applying TIS research to regions in the world that have so far not - or only sparsely - been covered, namely emerging economies and developing countries. If anything, varieties in institutional and organizational structures are even larger in these places, while reliability of regulatory institutions is far lower. This opens up new degrees of freedom on how technological change may happen in these contexts, where the relevance for sustainable technology development is hard to question. But even beyond that, transporting TIS studies to the Global South might inspire the 
formulation of major conceptual innovations in TIS research (see, e.g., Blum et al., in press; Gosens et al., 2015; Jacobsson and Bergek, 2006; Murphy, 2013; Tigabu et al., 2015).

The second problem area that emerges when coupling TIS with spatial context structures relates to issues of multi-scalarity. As a start, it is important to recall that the TIS concept was originally formulated as a critique of territorial innovation system concepts (Carlsson and Stankiewicz, 1991; see also Oinas and Malecki, 2002), by explicitly claiming that system formation processes normally run across any pre-set territorial boundaries. Indeed, Carlsson (2006) diagnosed that the majority of innovation systems research (including NIS, RIS and SIS) was not able to adequately address the growing globalization of innovative activities and urged for explicitly adopting an international view on innovation processes. In a multi-scalar perspective it is often hard to decide where actors, networks and institutions are actually located.

Multinational firms, for instance, may be active in a specific region, but they are also connected to many other places in the world. They will therefore create structural couplings with all those geographical contexts they are active in. As a consequence, their corporate strategies will often reflect priorities which emerge out of overall considerations in their global value chains and not only focus on interests of a specific branch plant. We may therefore consider a transnational company (or any other internationally active actor group) as incorporating a strategic coupling with a potentially high number of territorial context structures. In order to understand conditions for successful regions, geographers have therefore repeated that it is important to study trans-local networks that are constituted by different dimensions of proximity, besides geographical also cultural, organizational or cognitive proximity (Boschma, 2005). In the regional studies literature in general, it is taken for granted that innovative regions do not only dependent on local embedding but equally on the ability of actors to access assets provided by global networks (Asheim and Isaksen, 2002; Bunnell and Coe, 2001; Maskell et al., 2006); Carlsson and Stankiewicz (1991). As a consequence, the prospering of an internationally extensive TIS may depend on the ability to differentially access assets that are available in many different territorial contexts.

The explicit conceptualization of scale opens up a whole number of new research questions. Several recent studies may be mentioned here: How can we analyze the coupled dynamics of several national TISs, which implement competing strategies of industrial policy (as in the case of PV TISs in China and Germany, see Quitzow (2013))? How can we understand the interrelationship between European national TISs and what may one day constitute a European TIS (for the case of off-shore wind, see Wieczorek et al. (2013))? How can we identify whether a specific TIS is global or whether it consists of a set of largely independent national and/or regional TISs (for the case of membrane bioreactor technology, see Binz et al. (2014))? More specifically for emerging economies: How can we analyze the opportunities or barriers for these countries to leapfrog certain development stages in industrial development or infrastructure build up (for urban water management, see Binz et al. (2012))? Or, how can we assess multi-scalar TIS dynamics within a specific country (for PV in Germany, see Dewald and Fromhold-Eisebith (2013))? Finally, how can we identify moments in TIS dynamics where manufacturing and market parts of the 
value chain start to follow spatially differential routes and by this create legitimacy problems for nationally framed demand-side policies (for German PV, see Dewald and Truffer (2012))?

\subsection{Interaction between a focal TIS and the political context}

It is recognized that interactions between focal TISs and the political context is at the heart of large-scale transformation processes (Freeman and Louçã, 2002) since they impact on the nature of institutional alignment, which includes alterations in norms, beliefs and regulations (Fuenfschilling and Truffer, 2014). The political context in which a TIS is embedded is, thus, of key importance to its development. Political support for a TIS materializes in, for example, the availability of public financial resources for research and development and the formation of markets, but also in increased societal legitimacy for the technological field that positively impacts on the entry of new actors that bring resources to the focal TIS, such as investors, entrepreneurs and local governments. The relation between the political context and the focal TIS can be seen as an example of a "type three" TIS-context interaction, as defined in section 2, in which structural couplings are created in the form of aligned institutions which enable the provision of specific resources that are essential for the further maturation of the TIS.

As institutional alignment enables access to resources and markets, firms individually and as a part of political networks compete to gain influence over institutions (Farla et al., 2012; Jacobsson and Bergek, 2004). As Van de Ven and Garud (1989, p. 210) put it: "firms not only compete in the market place but also in this political institutional context. Rival firms often cooperate to collectively manipulate the institutional context to legitimize and gain access to resources necessary for collective survival ..." From the perspective of an emerging TIS, this "manipulation" involves building legitimacy, creating positive expectations and influencing the adoption of regulations that shield markets and nurture innovations (Konrad et al., 2012; Smith and Raven, 2012; Ulmanen, 2013). For that purpose, engagement not only by political actors but also by actors from emerging TISs and social movements is required (Meadowcroft, 2011). An institutional alignment may even necessitate that political ideologies are influenced as these shape the understanding of acceptable solutions, including the appropriate role of government.

When firms and political networks engage in these type of activities they are influenced by the logic that dominate the focal TIS but also by the characteristics of the specific political system in which they are located. As such, these actors and networks become the embodiment of structural couplings between the focal TIS and the political system. A weakness of much of the TIS and transitions literature is, however, that the political circumstances that make the adoption of policies supporting a far reaching transformation likely is not addressed (Markard et al., in press). When the political system is explicitly considered as a contextual system, attention needs to be given to the characterization of the political system, including its dynamics, and how it constrains or enables the further development of the focal TIS. An example is Schenner (2011), who analyzes the politics behind the 'selection' of tradable green certificates in Sweden as a regulatory framework for governing investments in technologies that supply 
electricity from renewable energy sources. This framework impacts on all associated TISs and constitutes a major blocking mechanism of TIS dynamics beyond the demonstration phase, except for the currently most cost-effective technologies. She traces the roots of this choice to a political ideology which is strongly influenced by a core belief in the superiority of technology-neutral policies. This ideology is much due to the political influence of the large Swedish energy-intensive base industry (iron and steel, paper and pulp and chemical industries). The dominance of this ideology makes it a major challenge to influence the understanding of acceptable policy solutions so that these include technology-specific market formation policies. ${ }^{9}$ This leads to a lack of early markets for innovative capital goods suppliers, and a lack of local learning opportunities; a situation which is distinctly different from that in Germany where the rationale behind the EEG 2000 included early market formation as a driver of technical change and cost reduction (FME, 2000).

These differences in political context have major implications for TIS actors that engage in politics (e.g. lobbying activities). Smart politics in the Swedish context requires different framing than in the German case and the formation of a very broad renewable energy coalition to overcome the technology-neutral ideology. In Germany, technology-specific groups can more easily interact with the government, since technology-specific policies are better accepted by policy makers and, thus, easier to lobby for. Thus, due to differences in political contexts, the political strategies of TIS actors will differ.

The national differences in political processes are especially visible when a global TIS is studied as it is influenced by political processes in various geographical locations. Differences in forms of democracy (Lijphart, 2012), deeply rooted political beliefs (Sabatier and Jenkins-Smith, 1993), power structures and processes of politics (Hess, 2014) influence the political strategies of TIS actors as well as incumbents. The difference in policy tradition between California and Europe for zero emission mobility is illustrative. The Californian zero emission mandate was set up as a technology-forcing program to strongly affect innovation choices of large automakers. Wesseling et al. (2014) showed that it led to a wide range of lobbying activities by incumbent automakers ranging from filing amendments and litigation strategies to conforming strategies. Europe, on the other hand, has chosen a gradual increase of emission norms over time and this evoked a different lobbying strategy of large automakers.

However, as was mentioned in section 3.2, the political process frequently also has features which are specific to a sector, even if national characteristics influence politics in a general way, i.e. politics is a dimension that cuts across geography, sectors and technologies. An illustrative case of the dynamics of

\footnotetext{
${ }^{9}$ This challenge is not limited to TISs generating electricity but is also found in the TISs centred around other technologies in other sectors, such as gasified biomass (vehicle fuel) and electric vehicles (Sandén and Jacobsson, 2014). Political processes may, therefore, have sectoral commonalities which can be traced to the geographical dimension. These commonalities are determined by more than the interests of dominant industries. According to the Varieties of Capitalism literature (Hall and Soskice, 2001) the characteristics of the political process are countryspecific and can be categorized in two ideal types: Liberal Market Economies (LME) and Coordinated Market Economies (CME).
} 
sector-level politics, and the interdependent dynamics of various structurally coupled TISs in the electricity generating sector, is the German debate about the "Energiewende". Whereas most large utilities opposed the Energiewende from its start but failed in their opposition (Jacobsson and Lauber, 2006), the large German utilities have come to face an existential threat as a consequence of the rapid deployment of renewable electricity production. In response, utilities (Enel et al., 2013) and other members of a discourse coalition favouring conventional power generation made even stronger attempts to delegitimize the sectoral policy framework supporting renewables (EEG), arguing that it involves "over-subsidized" and "unaffordable" technologies.

Influenced by this narrative, which was also shared by the European Commission, the new German government (2014) made substantial changes in the policy framework which involves slower phase-out for coal plants, reduced compensation for onshore wind, slower deployment for offshore wind and drastic reductions for new biomass capacity. Indeed, the impact on the offshore wind TIS comes at a point in its development where it puts at risk the formation of a complete and large enough supply chain to contribute to the replacement of coal in time (Lauber and Jacobsson, 2013), which is highly significant given the German long-standing focus on building strong capital goods industries. ${ }^{10}$ Hence, the discourse coalition managed to have a large impact on policy, in spite of the enduring strength of opposing actors in the German political landscape, such as popular movements, Länder governments and a well-developed German capital goods industry.

When the political context is explicitly considered it raises questions like: How do TIS actors forge political networks or coalitions that work towards policy changes in favour of the focal technology (Jacobsson and Bergek, 2004; Musiolik and Markard, 2011; Negro and Hekkert, 2008)? How do different political context structures impact on the lobbying strategies by advocates of new technologies (Kitschelt, 1986; Sabatier, 1998)? What kind of policy networks and coalitions support or obstruct TISs that are associated with far-reaching changes in existing sectors (Kern and Smith, 2008; Markard et al., in press)? Which political systems are more conducive for technology-specific support policies? Next to these research questions, the type of policy recommendations that follow from a TIS analysis may change. Up till now, most policy recommendations do not take the political environment of the target audience (policy-makers) into account. By a more explicit focus on the political context, policy recommendations can take into account the daily practices and social and political embedding of policy-makers. Better advice may also be given to advocates of emerging technologies on how to conduct various lobbying activities.

\footnotetext{
${ }^{10}$ As this example shows, the politics of institutional alignment may, thus, influence not only 'legitimation' but also 'market formation'. Subsequently, it may lead firms in the value chain to search for business opportunities elsewhere ('influence (guidance) on the direction of search) and to reduce 'resource mobilisation'.
} 


\section{Conclusions and implications for analysts}

In this paper we argue that the dynamics of technological innovation systems are influenced by a variety of contextual structures and we go some way towards an elaborated conceptualization of such contexts. We describe context structures as organizational fields, which exhibit some degree of institutional coherence. We also distinguish between two broad kinds of interaction - external links and structural couplings - which are characterized by different degrees of interdependence between a focal TIS and specific context structures. We discuss four types of contexts in more detail. First, developments in a focal TIS are influenced by developments in other TIS. This interaction can be both supportive and competitive. Second, there is mutual interaction between TISs and sectors. A sector comprises multiple TISs supplying technologies and products needed to serve a certain function for prospective users. Interaction takes place due to sector specific regulations, norms and cognitive frames, and physical infrastructures. Third, we discerned a geographical dimension of TIS context structures. Technological developments are not evenly distributed over space and regional structures impact technology development and diffusion in different ways. Finally, we discerned a political dimension in which a "battle over institutions" takes place.

As briefly discussed in Section 2, this conceptualization has some limitations. First, we fully acknowledge that there are other relevant context structures than the four we discuss in this paper. ${ }^{11}$ However, even though we did not provide an exhaustive list of all relevant context structures, we still expect that the elaborations made in this paper provide a sort of template for analyzing other context structures in the future. Second, the four context structures might not be neatly separated in an empirical setting. The point made here is, however, that depending on the purpose of the study we can focus on a particular context structure to investigate its dynamics and links to the focal TIS. We can, thus, think of the contexts as mutually excluding conceptual magnifying glasses, which each brings specific things to the foreground and which together provide a more complete picture of an empirical case.

The implications of an explicit, and richer, conceptualization of TIS contexts for analysts are significant. On the positive side, it facilitates finding the origins of systemic problems which may then be tackled by different types of interventions. It highlights that a thorough understanding of the TIS in question has to be supplemented with insights into the dynamics of a set of contexts and their interactions with the TIS. The first and main lesson for analysts is, therefore, the diversity of issues that can be included in TIS studies, from e.g. politics of institutional change, which can be analyzed via the discourses of various political networks, to technological couplings with other TIS, within as well as beyond sector boundaries.

The second lesson is that the analyst needs to acquire a thorough understanding of industrial dynamics, which includes a more than superficial grasp of the technologies involved and draws on insight from many

\footnotetext{
${ }^{11}$ For examples of interaction with the educational and financial systems, see Jacobsson and Karltorp (2012, 2013).
} 
different scientific disciplines. This is necessary in order to understand the significance of interactions with complementary TISs, e.g. infrastructure, and of couplings of technological nature where the focal TIS may benefit from the knowledge base and products generated in other TISs.

The third lesson is that analysts should tread warily when setting the technological and territorial boundaries within which they want to analyze a specific TIS. Ideally, for the case of territorial boundaries, they would first identify the global set of TIS-elements and functions and then determine whether their preferred spatial delimitation represents a sufficiently interconnected sub-system in the global TIS. Furthermore, an analyst should carefully identify which sort of "external factors" have to be taken into account and whether these are sufficiently independent of each other to be treated as isolated forces. If not, the system boundary would have to be redefined in order to allow for more complex system topologies. For instance, the analysis would consist of a set of nested TISs if a national TIS is heavily influenced by higher-order policies (e.g. as in the case of a national offshore wind TIS being part of a European TIS). Another case could be if a TIS analysis was framed as the coupled dynamics of two national TISs (cf. Bento and Fontes, 2015).

Finally, up till now TIS studies have mainly contributed to insights into how specific technological trajectories unfold and what the policy and management implications are of these dynamics. However, by this explication of context, some of the necessary building blocks are in place to also study how the dynamics of one or several TISs impact on that context. Indeed, understanding the co-evolution of various TISs and sectoral dynamics is key to explaining societal transitions and a coherent framework incorporating contextual structures is expected to be a step towards a TIS-based model of socio-technical transitions.

\section{Acknowledgements}

Part of the work behind the paper received financial support through EIS - Strategic research alliance for Energy Innovation Systems and their dynamics. EIS is funded by the Danish Council for Strategic Research, the Programme Commission on Sustainable Energy and Environment, and by the participating research institutions. We thank Wouter Boon and three anonymous reviewers for useful comments on earlier versions of this paper.

\section{References}

Alkemade, F., Hekkert, M.P., Negro, S.O., 2011. Transition policy and innovation policy: Friends or foes? Environmental Innovation and Societal Transitions 1, 125-129.

Andersson, B.A., Jacobsson, S., 2000. Monitoring and assessing technology choice: the case of solar cells. Energy Policy 28, 1037-1049.

Arthur, W.B., 2009. The Nature of Technology. What It Is and How It Evolves. The Free Press, New York. 
Asheim, B., Isaksen, A., 2002. Regional Innovation Systems: The Integration of Local 'Sticky' and Global 'Ubiquitous' Knowledge. The Journal of Technology Transfer 27, 77-86.

Bento, N., Fontes, M., 2015. Spatial diffusion and the formation of a technological innovation system in the receiving country: The case of wind energy in Portugal. Environmental Innovation and Societal Transitions 15, 158-179.

Bergek, A., 2012. Ambiguities and challenges in the functions approach to TIS analysis: a critical literature review, International Conference on Sustainability Transitions, Copenhagen.

Bergek, A., Hekkert, M., Jacobsson, S., 2008a. Functions in innovation systems: A framework for analysing energy system dynamics and identifying goals for system-building activities by entrepreneurs and policy makers, in: Foxon, T., Köhler, J., Oughton, C. (Eds.), Innovation for a Low Carbon Economy: Economic, Institutional and Management Approaches. Edward Elgar, Cheltenham.

Bergek, A., Jacobsson, S., 2003. The Emergence of a Growth Industry: A Comparative Analysis of the German, Dutch and Swedish Wind Turbine Industries, in: Metcalfe, S., Cantner, U. (Eds.), Change, Transformation and Development. Physica-Verlag, Heidelberg, pp. 197-227.

Bergek, A., Jacobsson, S., Carlsson, B., Lindmark, S., Rickne, A., 2008b. Analyzing the functional dynamics of technological innovation systems: A scheme of analysis. Research Policy 37, 407429.

Bergek, A., Jacobsson, S., Sandén, B.A., 2008c. 'Legitimation' and 'development of positive externalities': Two key processes in the formation phase of technological innovation systems. Technology Analysis and Strategic Management 20, 575-592.

Bergek, A., Mignon, I., Sundberg, G., 2013. Who invests in renewable electricity production? Empirical evidence and suggestions for further research. Energy Policy 56, 568-581.

Binz, C., Truffer, B., Coenen, L., 2014. Why space matters in technological innovation systemsMapping global knowledge dynamics of membrane bioreactor technology. Research Policy 43, 138-155.

Binz, C., Truffer, B., Li, L., Shi, Y., Lu, Y., 2012. Conceptualizing leapfrogging with spatially coupled innovation systems: The case of onsite wastewater treatment in China. Technological Forecasting and Social Change 79, 155-171.

Blum, N.U., Bening, C.R., Schmidt, T.S., in press. An analysis of remote electric mini-grids in Laos using the Technological Innovation Systems approach. Technological Forecasting and Social Change.

Boschma, R., 2005. Proximity and Innovation: A Critical Assessment. Regional Studies 39, 61-74. Brusoni, S., Prencipe, A., Pavitt, K., 2001. Knowledge Specialization, Organizational Coupling, and the Boundaries of the Firm: Why Do Firms Know More Than They Make? Administrative Science Quarterly 46, 597-621.

Bunnell, T.G., Coe, N.M., 2001. Spaces and scales of innovation. Progress in Human Geography 25, 569-589.

Carlsson, B., 2006. Internationalization of innovation systems: A survey of the literature.

Research Policy 35, 56-67.

Carlsson, B., Jacobsson, S., 1994. Technological systems and economic policy: the diffusion of factory automation in Sweden. Research Policy 23, 235-248.

Carlsson, B., Jacobsson, S., Holmén, M., Rickne, A., 2002. Innovation systems: analytical and methodological issues. Research Policy 31, 233-245.

Carlsson, B., Stankiewicz, R., 1991. On the nature, function and composition of technological systems. Journal of Evolutionary Economics 1, 93-118.

Chang, Y.-C., Chen, M.-H., 2004. Comparing approaches to systems of innovation: the knowledge perspective. Technology in Society 26, 17-37.

Coenen, L., Benneworth, P., Truffer, B., 2012. Toward a spatial perspective on sustainability transitions. Research Policy 41, 968-979. 
Dewald, U., Fromhold-Eisebith, M., 2013. Trajectories of sustainability transitions in scaletranscending innovation systems - a conceptual approach based on the case of photovoltaics, paper under review by Environmental Innovation and Societal Transitions.

Dewald, U., Truffer, B., 2011. Market formation in technological innovation systems-diffusion of photovoltaic applications in Germany. Industry and Innovation 18, 285-300.

Dewald, U., Truffer, B., 2012. The Local Sources of Market Formation: Explaining Regional

Growth Differentials in German Photovoltaic Markets. European Planning Studies 20, 397-420.

Dosi, G., 1982. Technological paradigms and technological trajectories: A suggested

interpretation of the determinants and directions of technical change. Research Policy 11, 147-

162.

Enel, Eni, E.ON, Gas Natural Fenosa, GasTerra, GDF SUEZ, Iberdrola, RWE, Vattenfall, 2013.

Heads of nine leading European energy companies propose concrete measures to rebuild

Europe's energy policy.

Farla, J., Markard, J., Raven, R., Coenen, L., 2012. Sustainability transitions in the making: A

closer look at actors, strategies and resources. Technological Forecasting and Social Change 79, 991-998.

FME, 2000. Act on Granting Priority to Renewable Energy Sources. Explanatory Memorandum, German Federal Ministry for the Environment, Nature Conservation and Nuclear Safety, Berlin.

Freeman, C., Louçã, F., 2002. As time goes by: From the industrial revolutions to the information revolution. Oxford University Press, Oxford.

Fridlund, M., 1993. The "Development Pair" as a Link between Systems Growth and Industrial Innovation, Trita HST Working Paper. Departmen of History of Science and Technology, Royal Institute of Technology, Stockholm.

Fuenfschilling, L., Truffer, B., 2014. The structuration of socio-technical regimes-Conceptual foundations from institutional theory. Research Policy 43, 772-791.

Garud, R., Karnøe, P., 2003. Bricolage versus breakthrough: distributed and embedded agency in technology entrepreneurship. Research Policy 32, 277-300.

Geels, F.W., 2002. Technological transitions as evolutionary reconfiguration processes: a multilevel perspective and a case-study. Research Policy 31, 1257-1274.

Geels, F.W., 2004. From sectoral systems of innovation to socio-technical systems: Insights about dynamics and change from sociology and institutional theory. Research Policy 33, 897-920. Geels, F.W., Schot, J., 2007. Typology of sociotechnical transition pathways. Research Policy 36, 399-417.

Gosens, J., Lu, Y., Coenen, L., 2015. The role of transnational dimensions in emerging economy 'Technological Innovation Systems' for clean-tech. Journal of Cleaner Production 86, 378-388. Haley, B., 2015. Low-carbon innovation from a hydroelectric base: The case of electric vehicles in Québec. Environmental Innovation and Societal Transitions 14, 5-25.

Hall, P.A., Soskice, D., 2001. Varieties of Capitalism: The Institutional Foundations of

Comparative Advantage. Oxford University Press, Oxford.

Hekkert, M.P., Suurs, R.A.A., Negro, S.O., Kuhlmann, S., Smits, R.E.H.M., 2007. Functions of innovation systems: A new approach for analysing technological change. Technological Forecasting and Social Change 74, 413-432.

Hess, D.J., 2014. Sustainability transitions: A political coalition perspective. Research Policy 43, 278-283.

Hillman, K.M., Suurs, R.A.A., Hekkert, M.P., Sanden, B.A., 2008. Cumulative causation in biofuels development: A critical comparison of the Netherlands and Sweden. Technology Analysis and Strategic Management 20, 593-612.

Jacobsson, S., Bergek, A., 2004. Transforming the energy sector: the evolution of technological systems in renewable energy technology. Industrial and Corporate Change 13, 815-849. 
Jacobsson, S., Bergek, A., 2006. A framework for guiding policy-makers intervening in emerging innovation systems in 'catching-up' countries. European Journal of Development Research 18, 687-707.

Jacobsson, S., Karltorp, K., 2012. Formation of competences to realize the potential of offshore wind power in the European Union. Energy Policy 44, 374-384.

Jacobsson, S., Karltorp, K., 2013. Mechanisms blocking the dynamics of the European offshore wind energy innovation system - Challenges for policy intervention. Energy Policy 63, 1182-

1195.

Jacobsson, S., Lauber, V., 2006. The politics and policy of energy system transformationexplaining the German diffusion of renewable energy technology. Energy Policy 34, 256-276. Jacobsson, T., Jacobsson, S., 2014. Conceptual confusion - an analysis of the meaning of concepts in technological innovation systems and sociological functionalism. Technology Analysis \& Strategic Management, 1-13.

Johnson, A., Jacobsson, S., 2001. Inducement and Blocking Mechanisms in the Development of a New Industry: The Case of Renewable Energy Technology in Sweden, in: Coombs, R., Green, K., Walsh, V., Richards, A. (Eds.), Technology and the Market: Demand, Users and Innovation. Edward Elgar, Cheltenham/Northhampton.

Karltorp, K., Sandén, B.A., 2012. Explaining regime destabilisation in the pulp and paper industry. Environmental Innovation and Societal Transitions 2, 66-81.

Kemp, R., Schot, J., Hoogma, R., 1998. Regime shifts to sustainability through processes of niche formation: The approach of strategic niche management. Technology Analysis \& Strategic Management 10, 175-198.

Kern, F., Smith, A., 2008. Restructuring energy systems for sustainability? Energy transition policy in the Netherlands. Energy Policy 36, 4093-4103.

Kitschelt, H.P., 1986. Political Opportunity Structures and Political Protest: Anti-Nuclear Movements in Four Democracies. British Journal of Political Science 16, 57-85.

Kivimaa, P., Virkamäki, V., 2014. Policy Mixes, Policy Interplay and Low Carbon Transitions: The Case of Passenger Transport in Finland. Environmental Policy and Governance 24, 28-41. Konrad, K., Markard, J., Ruef, A., Truffer, B., 2012. Strategic responses to fuel cell hype and disappointment. Technological Forecasting and Social Change 79, 1084-1098.

Lauber, V., Jacobsson, S., 2013. The politics and economics of constructing, contesting and restricting socio-political space for renewables - the case of the German Renewable Energy Act, International workshop on low carbon innovation politics, Eindhoven University, Eindhoven, 26-28 November 2013.

Lauber, V., Mez, L., 2004. Three decades of renewable electricity policies in Germany. Energy \& Environment 15, 599-623.

Lieberherr, E., Truffer, B., 2014. Governance Modes and Innovativeness: A comparative analysis of dynamic capabilities in three water utilities, paper under review by Environmental Innovation and Sustainability Transitions.

Lijphart, A., 2012. Patterns of democracy: Government forms and performance in thirty-six countries. Yale University Press, New Haven.

Lovio, R., Kivimaa, P., 2012. Comparing Alternative Path Creation Frameworks in the Context of Emerging Biofuel Fields in the Netherlands, Sweden and Finland. European Planning Studies 20, 773-790.

Malerba, F., 2002. Sectoral systems of innovation and production. Research Policy 31, 247-264.

Markard, J., Raven, R., Truffer, B., 2012. Sustainability transitions: An emerging field of research and its prospects. Research Policy 41, 955-967.

Markard, J., Suter, M., Ingold, K., in press. Socio-technical transitions and policy change Advocacy coalitions in Swiss energy policy. Environmental Innovation and Societal Transitions. Markard, J., Truffer, B., 2006. Innovation processes in large technical systems: Market liberalization as a driver for radical change? Research Policy 35, 609-625. 
Markard, J., Truffer, B., 2008. Technological innovation systems and the multi-level perspective: Towards an integrated framework. Research Policy 37, 596-615.

Markard, J., Wirth, S., Truffer, B., 2014. Institutional dynamics in emerging technological fields and their context - legitimacy of biogas technology in Germany, mimeo, ETH/EAWAG, Zürich. Maskell, P., Bathelt, H., Malmberg, A., 2006. Building global knowledge pipelines: The role of temporary clusters. European Planning Studies 14, 997-1013.

McDowall, W., Ekins, P., Radošević, S., Zhang, L.-y., 2013. The development of wind power in China, Europe and the USA: how have policies and innovation system activities co-evolved? Technology Analysis \& Strategic Management 25, 163-185.

Meadowcroft, J., 2011. Engaging with the politics of sustainability transitions. Environmental Innovation and Societal Transitions 1, 70-75.

Meelen, T., Farla, J., 2013. Towards an integrated framework for analysing sustainable innovation policy. Technology Analysis \& Strategic Management 25, 957-970.

Murphy, J.T., 2013. Human Geography and Transition Studies: Promising Intersections, paper under review by Environmental Innovation and Societal Transitions.

Musiolik, J., Markard, J., 2011. Creating and shaping innovation systems: Formal networks in the innovation system for stationary fuel cells in Germany. Energy Policy 39, 1909-1922.

Musiolik, J., Markard, J., Hekkert, M., 2012. Networks and network resources in technological innovation systems: Towards a conceptual framework for system building. Technological

Forecasting and Social Change 79, 1032-1048.

Negro, S.O., Hekkert, M.P., 2008. Explaining the success of emerging technologies by innovation system functioning: the case of biomass digestion in Germany. Technology Analysis \& Strategic Management 20, 465-482.

Negro, S.O., Hekkert, M.P., Smits, R.E., 2007. Explaining the failure of the Dutch innovation system for biomass digestion-A functional analysis. Energy Policy 35, 925-938.

Oinas, P., Malecki, E.J., 2002. The Evolution of Technologies in Time and Space: From National and Regional to Spatial Innovation Systems. International Regional Science Review 25, 102-131. Onufrey, K., 2014. Technology dynamics in multi-technology industries: selection and variety creation through the lens of path dependency and path generation, Department of Management and Engineering. Linköping University, Linköping.

Onufrey, K., Bergek, A., 2015. Self-reinforcing mechanisms in a multi-technology industry: understanding sustained technological diversity in a context of path dependency. under review by a scientific journal.

Quitzow, R., 2013. Dynamics of a Policy-Driven Market: The Co-Evolution of Technological Innovation Systems for Solar PV in China and Germany, paper under review by Environmental Innovation and Societal Transitions.

Rip, A., Kemp, R., 1998. Technological Change, in: Rayner, S., Malone, E.L. (Eds.), Human choice and climate change - Resources and technology. Battelle Press, Columbus, pp. 327-399.

Rothaermel, F.T., 2001. Complementary assets, strategic alliances, and the incumbent's advantage: an empirical study of industry and firm effects in the biopharmaceutical industry. Research Policy 30, 1235-1251.

Sabatier, P.A., 1998. The advocacy coalition framework: revisions and relevance for Europe. Journal of European Public Policy 5, 98-130.

Sabatier, P.A., Jenkins-Smith, H.C., 1993. Policy change and learning: An advocacy coalition approach. Westview Press, Boulder (CO).

Sandén, B.A., Hillman, K.M., 2011. A framework for analysis of multi-mode interaction among technologies with examples from the history of alternative transport fuels in Sweden. Research Policy 40, 403-414.

Sandén, B.A., Jacobsson, S., 2014. Teknikpolitiska lärdomar, in: Hellsmark, H. (Ed.), Teknologiska innovationssystem inom energiområdet. En praktisk vägledning till identifiering av 
systemsvagheter som motiverar särskilda politiska åtaganden, ER 2014:23. Statens energimyndighet, Eskilstuna, pp. 261-286.

Schenner, E., 2011. Policy Instrument Selection in Environmental Politics: The Political Career of Tradable Green Certificates in the EU and Sweden. University of Salzburg, Salzburg, Austria. Schmidt, T., Dabur, S., 2014. Explaining the diffusion of biogas in India: a new functional approach considering national borders and technology transfer. Environ Econ Policy Stud 16, 171-199.

Sharif, N., 2006. Emergence and development of the National Innovation Systems concept. Research Policy 35, 745-766.

Smith, A., Raven, R., 2012. What is protective space? Reconsidering niches in transitions to sustainability. Research Policy 41, 1025-1036.

Smits, R.E.H.M., Kuhlmann, S., Shapira, P., 2010. The Theory and Practice of Innovation Policy. Edward Elgar, Cheltenham.

Suurs, R.A.A., Hekkert, M.P., 2009a. Competition between first and second generation technologies: Lessons from the formation of a biofuels innovation system in the Netherlands. Energy 34, 669-679.

Suurs, R.A.A., Hekkert, M.P., 2009b. Cumulative causation in the formation of a technological innovation system: The case of biofuels in the Netherlands. Technological Forecasting and Social Change 76, 1003-1020.

Tigabu, A.D., Berkhout, F., van Beukering, P., 2015. The diffusion of a renewable energy technology and innovation system functioning: Comparing bio-digestion in Kenya and Rwanda. Technological Forecasting and Social Change 90, 331-345.

Truffer, B., Coenen, L., 2012. Environmental Innovation and Sustainability Transitions in Regional Studies. Regional Studies 46, 1-21.

Truffer, B., Markard, J., Binz, C., Jacobsson, S., 2012. A literature review on Energy Innovation Systems: Structure of an emerging scholarly field and its future research directions. Radar-Paper of the strategic research alliance for Energy Innovation Systems and their dynamics, Dübendorf / Gothenburg.

Ulmanen, J.H., 2013. Exploring policy protection in biofuel niche development. A policy and Strategic Niche Management analysis of Dutch and Swedish biofuel development, 1970-2010, Department of Industrial Engineering and Innovation Sciences. Technische Universiteit Eindhoven, Eindhoven.

Unruh, G.C., 2000. Understanding carbon lock-in. Energy Policy 28, 817-830.

van de Ven, A.H., Garud, R., 1989. A framework for understanding the emergence of new industries, in: Rosenbloom, R., Burgelman, R. (Eds.), Research on technological innovation and management policy. JAI Press, Greenwich, CT, pp. 195-226.

Vasseur, V., Kamp, L.M., Negro, S.O., 2013. A comparative analysis of Photovoltaic

Technological Innovation Systems including international dimensions: the cases of Japan and The Netherlands. Journal of Cleaner Production 48, 200-210.

Weber, K.M., Rohracher, H., 2012. Legitimizing research, technology and innovation policies for transformative change: Combining insights from innovation systems and multi-level perspective in a comprehensive 'failures' framework. Research Policy 41, 1037-1047.

Wesseling, J.H., Farla, J.C.M., Sperling, D., Hekkert, M.P., 2014. Car manufacturers' changing political strategies on the ZEV mandate. Transportation Research Part D: Transport and Environment 33, 196-209.

Wieczorek, A., Hekkert, M.P., Harmsen, R., 2013. Interrelatedness of national offshore wind Innovation Systems: implications for policy, paper under review by Environmental Innovation and Societal Transitions (revision).

Wieczorek, A.J., Hekkert, M.P., 2012. Systemic instruments for systemic innovation problems: A framework for policy makers and innovation scholars. Science and Public Policy 39, 74-87. 
Wirth, S., Markard, J., 2011. Context matters: How existing sectors and competing technologies affect the prospects of the Swiss Bio-SNG innovation system. Technological Forecasting and Social Change 78, 635-649.

Wirth, S., Markard, J., Truffer, B., Rohracher, H., 2013. Informal institutions matter: Professional culture and the development of biogas technology. Environmental Innovation and Societal Transitions 8, 20-41.

von Hippel, E., 2005. Democratizing innovation: The evolving phenomenon of user innovation. JfB 55, 63-78.

Wooten, M., Hoffmann, A., 2008. Organizational fields: Past, present and future, in: Greenwood, R., Oliver, C., Suddaby, R., Sahlin, K. (Eds.), The SAGE Handbook of Organizational Institutionalism. Sage, London. 